\title{
Vertiginous Symptoms and Objective Measures of Postural Balance in Elderly People with Benign Paroxysmal Positional Vertigo Submitted to the Epley Maneuver
}

\author{
Camila Nicácio da Silva ${ }^{1}$ Karyna Myrelly O. B. de Figueiredo Ribeiro ${ }^{2}$ Raysa Vanessa de Medeiros Freitas ${ }^{3}$ \\ Lidiane Maria de Britho Macedo Ferreira ${ }^{4}$ Ricardo Oliveira Guerra ${ }^{1,2}$
}

1 Post-Graduation Program of Physiotherapy, Universidade Federal do Rio Grande do Norte (UFRN), Natal, Rio Grande do Norte, Brazil 2 Post-Graduation Program in Health Sciences, UFRN, Natal, Rio Grande do Norte, Brazil

3 Department of Physiotherapy, UFRN, Natal, Rio Grande do Norte, Brazil

4 Post-Graduation Program in Public Health, UFRN, Natal, Rio Grande do Norte, Brazil

Int Arch Otorhinolaryngol 2016;20:61-68.

\author{
Address for correspondence Camila Nicácio da Silva, MSc, \\ Department of Physiotherapy, Universidade Federal do Rio Grande do \\ Norte, Avenida Senador Salgado Filho, 300, Campus Universitário \\ Natal Rio Grande do Norte 59078-970, Brazil \\ (e-mail: camila_nicacio@yahoo.com.br).
}

\begin{abstract}
Keywords

- vestibular diseases

- postural balance

- aged

- rehabilitation

Introduction Benign Paroxysmal Positional Vertigo (BPPV) is one of the most common and treatable causes of peripheral vestibular vertigo in adults. Its incidence increases with age, eventually leading to disability and a decreased quality of life.

Objective The research aims to assess short-term effects of Otolith Repositioning Maneuver (ORM) on dizziness symptoms, quality of life, and postural balance in elderly people with Benign Paroxysmal Positional Vertigo.

Methods A quasi-experimental study, which evaluated 14 elderly people that underwent the Otolith Repositioning Maneuver and reevaluation after one week. The authors performed statistical analysis by descriptive analysis of central tendency and dispersion; for pre- and post-treatment conditions, the authors used the Wilcoxon test.

Results All aspects of the Dizziness Handicap Inventory (physical, functional, emotional, and total scores) as well as the Visual Analogue Scale (VAS) decreased after therapy ( $p<0.05$ and $p=0.001$, respectively). However, more than half of the elderly participants did not achieve negative Dix-Hallpike. Regarding static and dynamic balance, there were significant differences in some parameters of the modified Clinical Test of Sensory Interaction and Balance, Limits of Stability and gait assessment measured by the Dizziness Gait Index $(p<0.05)$.

Conclusion Results reveal clinical and functional benefits in elderly people with Benign Paroxysmal Positional Vertigo submitted to Otolith Repositioning Maneuver. However, most of the participants did not overcome Benign Paroxysmal Positional Vertigo and not all aspects of postural balance improved. Therefore, a longer follow-up period and a multidisciplinary team are required to establish comprehensive care for elderly patients with dizziness complaints.
\end{abstract}

received

June 18,2015

accepted

August 20, 2015

published online

October 19, 2015
DOI http://dx.doi.org/

10.1055/s-0035-1565915. ISSN $1809-9777$.
Copyright $\odot 2016$ by Thieme Publicações License terms

Ltda, Rio de Janeiro, Brazil 


\section{Introduction}

Demographic projections have pointed out that Brazil will have around 33 million elderly people by 2025 (this is following the world trend), and will have twice the number of elderly over the next 20 years. ${ }^{1}$ Therefore, there are many concerns regarding the welfare of the elderly, in that which concerns the maintenance of an independent and autonomous lifestyle and seeking better quality of life for this population. $^{2}$

Some alterations due to aging are directly related to the vestibular system, which may cause multiple otoneurological-associated symptoms, such as vertigo and other types of dizziness, hearing loss, tinnitus, alterations in body balance, gait disturbance, and occasional falls. ${ }^{3}$ Falling results from a heterogeneous multifactorial geriatric syndrome and the seriousness of the complications that come from it increase with age; however, fall prevention has been largely neglected in clinical practice. ${ }^{4}$ One of the factors that may increase the risk of falling in elderly people is the presence of vestibular disorders, due to their effect on body balance. $^{3}$

Posture control is considered a complex motor skill derived from the interaction of neural and skeletal muscle systems. Neural components involve motor and sensorial processing, internal representation, and high levels of processing. This is essential to adaptive and anticipatory aspects regarding postural control, which involves the command of body position in space with two main purposes: orientation and stability. ${ }^{5}$ To obtain postural balance maintenance and to ensure adequate postural adjustments, it is necessary to combine vestibular, visual and somatosensory, central nervous and skeletal muscles systems, as well as internal representation of body orientation in space. ${ }^{6}$

Benign Paroxysmal Positional Vertigo (BPPV) is one of the most common and treatable causes of peripheral vestibular vertigo in adults, ${ }^{7-9}$ with an incidence of 64 per 100,000 people, with a higher incidence in elderly people. It is estimated that $25 \%$ occurs in 70 -year-old or older elderly population with complaints of dizziness, and most of them remain with these symptoms for over a year. ${ }^{10,11}$ BPPV prevalence is estimated to be $3.2 \%$ in women, $1.6 \%$ in men, and $2.4 \%$ in the general population. ${ }^{8}$ Von Brevern et al. concluded that, among the patients admitted to the emergency ward with moderate to severe vertigo and dizziness, 8 to $9 \%$ are diagnosed with BPPV. ${ }^{9}$

The physiopathology of BPPV is related to a displacement of the otoconia toward the semicircular canals (anterior, posterior, or lateral), which may remain floating in the endolymph of the semicircular canal (ductolithiasis or canalolithiasis) or adhere to the cupula (cupulithiasis), therefore altering the response of the canal to the head́s angular acceleration. $^{12}$

The BPPV of the posterior semicircular canal (SCC) is a specific type of BPPV, which is treated by the Epley maneuver and represents the most affected canal $(90.2 \%) .^{12,13}$ Confirmation of BPPV diagnosis in the posterior SCC is performed through the Dix-Hallpike test. ${ }^{14}$
Despite the use of the term "benign", this disease may cause considerable damage and incapacitate some patients. ${ }^{711,15}$ The condition may become incapacitating and compromise patientśs ability to perform simple daily life activities. The loss in quality of life is greater in periods of crisis, but these can also occur separately from crises in the form of physical or further alterations, such as functional and emotional ones. ${ }^{16-18}$

The knowledge of functional balance characteristics in elderly people with chronic vestibular dysfunction and the identification of variables associated to the loss of postural balance in these individuals can promote the development of specific prevention, assistance and rehabilitation strategies, to maintain autonomy and preserve the independence of the elderly for the longest time possible. ${ }^{3}$ Despite the large quantity of research demonstrating the effect of the Epley Maneuver on dizziness symptomatology, the literature still has little research that addresses clinical aspects of dizziness symptoms and quality of life, as well as postural balance after performing the Otolith Repositioning Maneuver (ORM) in elderly people with BPPV. Therefore, the present study aims to characterize elderly people with BPPV based on short-term effects of the modified Epley Maneuver on vertiginous symptoms, quality of life, and postural balance.

\section{Method}

This research was a quasi-experimental exploratory study. The target population was composed of elderly people residing in community who were referred from a university otoneurology outpatient unit.

The present project complied with the guidelines of resolution 466/12 of the National Health Council for research with human beings. The study obtained approval from the regional Ethics Review Board, registered under number 720.007. The participants received information about research procedures and objectives. Those who agreed to participate in the study signed an informed consent form.

The inclusion criteria for this study were individuals with an age equal to or greater than 65 years; clinical diagnosis of BPPV of the posterior semicircular canal; absence of neurological cervical symptoms; limited amplitude of cervical movement and instability to execute both the diagnostic Dix-Hallpike maneuver and the Otolithic Repositioning maneuvers; absence of systemic diseases without medical control and absence of functional limitations that impede independent walking; and being capable to sign the informed consent form. The research excluded subjects who presented serious health complications impeding the continuity of treatment or those with BPPV with bilateral involvement.

The evaluations for obtaining clinical data and objective measures of balance at baseline and after one week of treatment were conducted at a university geriatric physiotherapy laboratory.

The socio-demographic data evaluated included: age, sex, civil status, and level of education. Otoneurological data was BPPV diagnosis, number of associated vestibular effects, time 
of dizziness onset, type of dizziness, duration of dizziness, intensity of dizziness (measured by Visual Analogue Scale VAS), and associated symptoms, as well as nystagmus evaluated by the Videonystagmoscopy System (Contronic, Brazil).

Clinical and functional data evaluated included: number of associated diseases, number of medications, physical exercise level, and self-reported incapacity due to dizziness based on the Brazilian version of the Dizziness Handicap Inventory (DHI). We used the Balance Master System (NeuroCom International Inc., U.S.A.) to determine objective measures of static and dynamic balance evaluation and the Brazilian version of the Dynamic Gait Index (DGI) to assess balance.

In static balance, sway velocity was measured at four positions from the modified Clinical Test of Sensory Interaction on balance (on firm and foam surfaces with eyes open/ closed), by its composition (mean sway velocity at four test positions) and by the Unilateral Stance test with eyes open/ closed. For the statistical analysis of the data obtained in this test we considered the dominant leg. The participants made three attempts, each with duration of 10 seconds. For the dynamic balance, we measured movement velocity, maximum excursion, end point, and directional control data; all of which were obtained by the Limits of Stability (LOS). Tandem Walk and its end sway velocity were also part of the laboratory evaluation of the dynamic balance component of this research.

We used the DGI to evaluate the functional aspects of dynamic balance in BPPV patients. The DGI has a simple format and is considered a reliable instrument. ${ }^{19}$

At the baseline, we collected socio-demographic, otoneurological, quality of life, and functional aspects of gait and postural balance data. Subsequently, participants underwent the Dix-Hallpike test to identify which side needed ORM treatment. The maneuver would be repeated up to three times in session in case symptoms or signals persisted. Experienced physiotherapists in the field of Vestibular Rehabilitation performed both the tests and maneuvers. After one week, participants underwent the same evaluation protocol and those who presented positive Dix-Hallpike test underwent an additional ORM. Following each maneuver, the physiotherapists explained to the patients that the treatment could lead to vertigo and nausea, and in such cases, they asked patients to relax their cervical muscles to avoid injury in the region. Following ORM, participants were instructed to sleep on pillows with their head positioned halfway between flat and upright (a 45-degree angle) to avoid head inclination, such as when washing the hair in a salon or sitting in a dentist's chair, to avoid rough head movements, and to avoid laying on the treated side for 48 hours.

Initially, we performed the descriptive analysis of study variables through measures of central tendency and dispersion. We used the Shapiro-Wilk test for the distribution of data normality. To compare pre- and post-treatment results, we used the non-parametric Wilcoxon test. The adopted level of significance was $p<0.05$. For storage and processing of data, we used SPSS (Statistical Package for Social Sciences Version 20.0).

\section{Result}

The sample included 14 elderly people with a median age of 71 years (64-78 years old) who present ductolithiasis and subsequent semicircular canal as a pathophysiological basis. - Table 1 describes data on participantś socio-demographic and clinical characteristics.

According to characteristics of dizziness, two participants (14.3\%) presented dizziness for six months, five (35.7\%) for one or two years, three (21.4\%) for three or four years, and four $(31.3 \%)$ for five or more years.

Table 1 Socio-demographic characteristics, symptoms, and aspects related to dizziness in elderly people with BPPV

\begin{tabular}{|l|l|}
\hline Variables & Values* \\
\hline Age (years) & $71(64-78)$ \\
\hline BMI (kg/m $\left.{ }^{2}\right)$ & $26.1(20.9-35.0)$ \\
\hline Sex & \\
\hline Female & $11(78.6 \%)$ \\
\hline Male & $3(21.4 \%)$ \\
\hline Degree of schooling & \\
\hline Illiterate/unschooled & $2(14.3 \%)$ \\
\hline Primary school & $7(50.0 \%)$ \\
\hline High school & $4(28.6 \%)$ \\
\hline University & $1(7.1 \%)$ \\
\hline Civil status & \\
\hline Currently married/with partner & $4(28.6 \%)$ \\
\hline Not currently married/with partner & $10(71.4 \%)$ \\
\hline Time of dizziness onset (years) & $2.5(0.5-20)$ \\
\hline Age at dizziness onset (years) & $65(54-75)$ \\
\hline Side of lesion & \\
\hline Right & $12(85.7 \%)$ \\
\hline Left & $2(14.3 \%)$ \\
\hline Total number of comorbidities & $4.5(2-8)$ \\
\hline Total number of medications & $4.5(2-8)$ \\
\hline Practical physical activity & $13(92.8 \%)$ \\
\hline No activity & $9(64.3 \%)$ \\
\hline 3 days per week & $1(7.1 \%)$ \\
\hline 4 to 7 days per week & $4(28.6 \%)$ \\
\hline Presence of nystagmus & \\
\hline Yes & $10 \%)$ \\
\hline No & \\
\hline Dominant side & \\
\hline Right & $13 \%)$ \\
\hline Left & \\
\hline
\end{tabular}

Abbreviations: BMI, Body Mass Index.

*Values represent the Median (amplitude) or Absolute Frequency (relative frequency). 
The median number of ORM was 2.5 (2-3). After one week of treatment, five participants (35.7\%) presented a negative Dix-Hallpike test and nine (64.3\%) continued to present a positive Dix-Hallike test and underwent ORM again. Then, the median number of maneuvers was two $(0-3)$. When comparing the median number of maneuvers performed at initial evaluation and re-evaluation, we observed a significant reduction $(p<0.05)$.

According to the systemic diseases or supposed risk factors, which predispose or lead to BPPV development, the following conditions were found from the research $92.8 \%$ presented osteoarthritis, $64.3 \%$ systemic arterial hypertension (SAH), $42.9 \%$ osteoporosis, and $21.4 \%$ diabetes mellitus. Diseases were grouped and classified according to the International Classification of Diseases (ICD) and its absolute and relative distribution in the sample population is presented in - Table 2.

Of the 14 participants, nine (64.3\%) used medication that act on vertiginous symptoms including cinnarizine, flunarizine, betahistine, Ginkgo biloba, dimenhydrinate, and benzodiazepine (clonazepam) (-Fig. 1). - Table 3 show the quantity of medications used.

According to clinical data, there was a significant reduction in VAS scores between the initial evaluation and the one at one week following ORM. The participants presented greater improvement in self-perception of the incapacitating effects caused by dizziness, as evaluated by DHI, one week post-ORM in all aspects (physical, functional, emotional, and total score) (-Table 4).

Regarding static and dynamic postural balance, there was a significant difference in some parameters of the modified Sensory Interaction Test, the Limits of Stability, and gait by the Dizziness Gait Index $(p<0.05)$, and no significant difference in the Unilateral Stance and Tandem Walk tests (-Table 5).

\section{Discussion}

BPPV is the most common vestibular cause of vertigo. ${ }^{11,13,20-23}$ It is also one of the four otoneurological diseases of greatest prevalence among the geriatric population, causing a strong impact on the health and quality of life of these individuals. $^{24}$ Non-pharmacological alternatives for treatment of the disease (among them, the ORM) represent an important therapeutic opportunity because it does not present risks of adverse effects commonly present in elderly individuals that use pharmacological products.

Fife et al. classified the Epley maneuver for otolithic reposition as a "Level A recommendation." In other words, the therapy is effective and secure and should be offered to all posterior canal BPPV patients regardless of age. ${ }^{25}$ Various studies showed short-term positive results after ORM performance in BPPV treatment. These studies had a follow-up variation between 72 hours and 6 weeks, ${ }^{26-32}$ though there is no prognosis of a satisfactory outcome.

The present study aimed to evaluate the short-term effects of ORM in a group of elderly patients with BPPV symptoms. The majority of the subjects in this study were women
Table 2 Absolute and relative frequencies of associated diseases in elderly people with BPPV, classified according to the International Classification of Diseases (ICD)

\begin{tabular}{|c|c|c|}
\hline Diseases & (n) & $(\%)$ \\
\hline \multicolumn{3}{|c|}{ Endocrine, nutritional and metabolic diseases } \\
\hline Hypercholesterolemia & 8 & 57.1 \\
\hline Diabetes mellitus & 3 & 21.4 \\
\hline Thyroid nodules & 1 & 7.1 \\
\hline Hypothyroidism & 1 & 7.1 \\
\hline \multicolumn{3}{|l|}{ Mental and behavioral disorders } \\
\hline Depression & 4 & 28.6 \\
\hline \multicolumn{3}{|l|}{ Diseases of the nervous system } \\
\hline Sleep apnea & 1 & 7.1 \\
\hline \multicolumn{3}{|l|}{ Diseases of the eye and adnexa } \\
\hline Glaucoma & 1 & 7.1 \\
\hline \multicolumn{3}{|l|}{ Diseases of the circulatory system } \\
\hline Arterial hypertension & 9 & 64.3 \\
\hline Chronic venous insufficiency & 1 & 7.1 \\
\hline Atrial fibrillation & 1 & 7.1 \\
\hline \multicolumn{3}{|l|}{ Diseases of the respiratory system } \\
\hline Asthma & 3 & 21.4 \\
\hline Chronic bronchitis & 1 & 7.1 \\
\hline Chronic sinusitis & 1 & 7.1 \\
\hline \multicolumn{3}{|l|}{ Diseases of the digestive system } \\
\hline Gastritis & 4 & 28.6 \\
\hline \multicolumn{3}{|l|}{$\begin{array}{l}\text { Diseases of the musculoskeletal } \\
\text { system and connective tissue }\end{array}$} \\
\hline Osteoarthritis & 13 & 92.8 \\
\hline Osteoporosis & 6 & 42.9 \\
\hline Osteopenia & 1 & 7.1 \\
\hline Systemic lupus erythematosus & 1 & 7.1 \\
\hline \multicolumn{3}{|l|}{ Diseases of the genitourinary system } \\
\hline Hyperplasia of Prostate & 2 & 14.3 \\
\hline \multicolumn{3}{|l|}{$\begin{array}{l}\text { Unclassified symptoms, signals and } \\
\text { abnormal findings from clinical } \\
\text { and laboratory exams }\end{array}$} \\
\hline Pre-diabetes & 2 & 14.3 \\
\hline
\end{tabular}

(78.6\%), which corroborated with previous studies. ${ }^{11,33}$ The high incidence of BPPV in women can be explained by their biological aspects such as the reduction in hormone levels following menopause. Recent studies related to the hormonal dysfunction observed a decrease in estrogen and disturbances in calcium metabolism in this population, which may induce changes in the structure of otoconia, similar to the alterations observed in bone mass, leading to osteopenia and osteoporosis. ${ }^{34,35}$ 


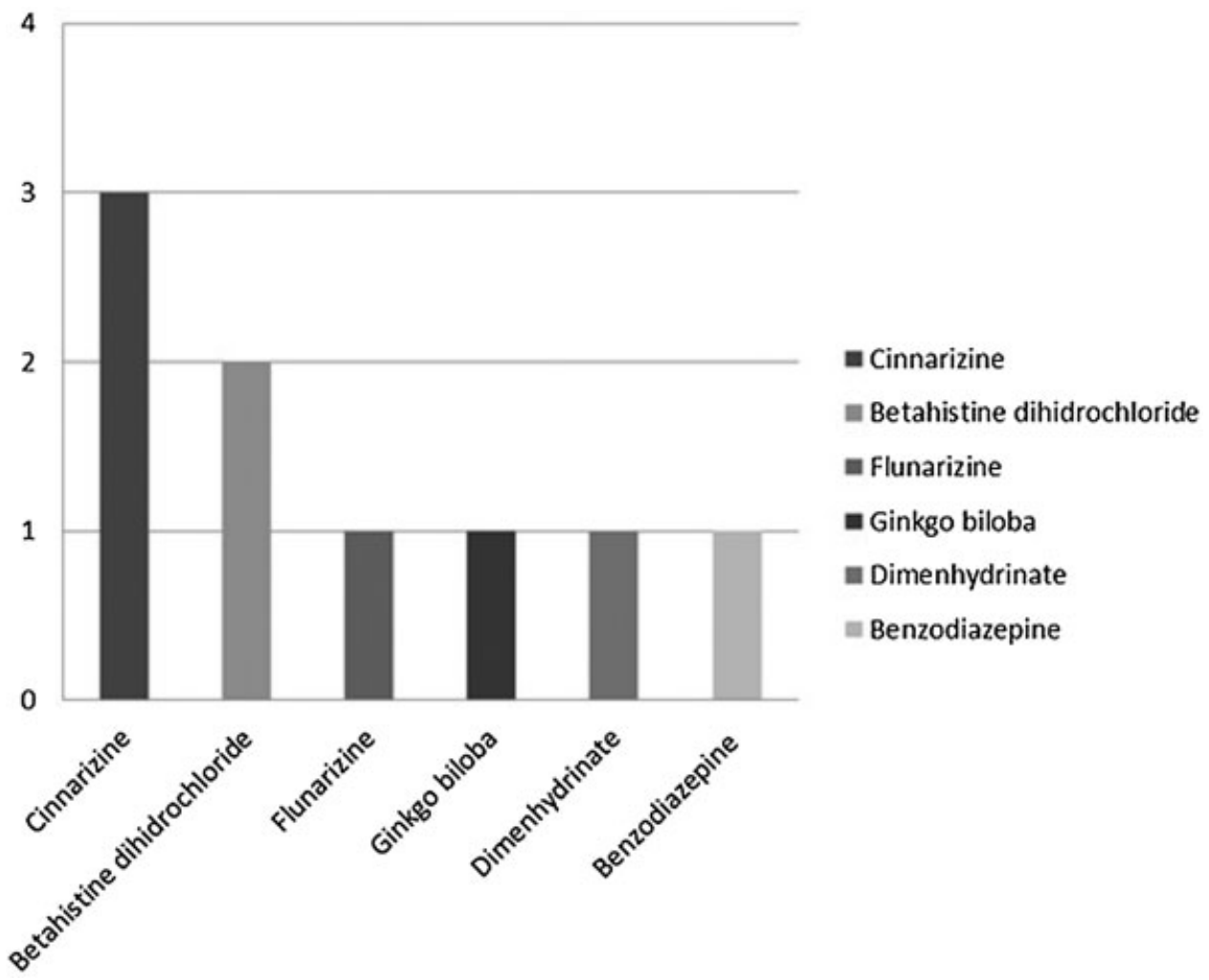

Fig. 1 Distribution of medications acting on vertiginous symptoms used by elderly BPPV patients.

Iatrogenic of pharmaceutical medications may be one of the potential causes of Dizziness. There are many medications that act as vestibular system suppressors, the most common being benzodiazepines and anti-histamines. Benzodiazepines can reduce the sensation of rotatory dizziness and, at the same time, interfere in the central compensation of peripheral vestibular conditions. On the other hand, antihistamines act on the emetic nerve center suppression, relieving nausea and vomiting associated with illness. Current medications that control vertiginous symptoms, when used in the short term, can be prescribed when the patient refuses ORM therapy or when the symptoms are unbearable and persist following ORM. ${ }^{36}$

Despite achieving release from vertigo symptoms, more than half of elderly did not achieve BPPV resolution. This may be explained by the presence of comorbidities, given that there is an increasing risk of dizziness complaints in relation to the number of associated illnesses. ${ }^{37,38}$ Cardiovascular, metabolic, and osteoarthritic diseases are more commonly associated with the vestibulopathy and relate to its genesis. ${ }^{33,39,40}$ A recent study demonstrated that only systemic arterial hypertension is capable of significantly influencing the number of BPPV recurrences, a fact that also occurred in the presence of isolated diabetes and osteoarthritis. Osteoporosis can be associated to SAH, diabetes, and osteoarthritis, which constitute an increased risk in the rate of BPPV recurrence. ${ }^{41}$ In the present study, these conditions were present in the majority of the sample population, mostly prevalent as osteoarthritis (92.8\%) and SAH (64.3\%).

Another source of vertiginous symptoms may be related to health habits. The literature points to sedentary lifestyle as an important risk factor for the onset of dizziness, since when there is decreased movement and more time resting in bed, elderly people develop an increased probability of developing dizziness through inhibition of vestibular reflexes, fear, and/ or loss of self-confidence. ${ }^{42}$ A recent cross-sectional study that included 491 elderly participants confirmed there is an association between BPPV and lack of physical activity in women. ${ }^{43}$ Thus, sedentary elderly people present more

Table 3 Distribution of absolute and relative frequencies categorized by number of medications used by elderly BPPV patients

\begin{tabular}{|l|l|l|l|}
\hline \multirow{3}{*}{ Number of medications } & Categories & Absolute frequency (n) & Relative frequency (\%) \\
\cline { 2 - 4 } & 1 or 2 medications & 1 & 7.1 \\
\cline { 2 - 4 } & 3 or 4 medications & 6 & 42.9 \\
\cline { 2 - 4 } & 5 or more medications & 7 & 50.0 \\
\hline
\end{tabular}


Table 4 Comparison of medians pre and postmodified Epley maneuver regarding vertigo symptoms (VAS) and quality of life $(\mathrm{DHI})$

\begin{tabular}{|l|l|l|l|}
\hline & Pre-Epley & Post-Epley & $p^{*}$ \\
\hline VAS & $8(5-10)$ & $3,5(0-7)$ & 0.001 \\
\hline Physical DHI & $18(10-26)$ & $6(0-26)$ & 0.002 \\
\hline Functional DHI & $10(0-24)$ & $3(0-16)$ & 0.002 \\
\hline Emotional DHI & $8(0-30)$ & $4(0-28)$ & 0.025 \\
\hline Total DHI Score & $39(22-84)$ & $15(0-72)$ & 0.001 \\
\hline
\end{tabular}

Abbreviations: DHI, Dizziness Handicap Inventory; VAS, Visual Analogue Scale.

Values represent the Median (amplitude); ${ }^{*} \mathrm{p}<0.05$, by the nonparametric Wilcoxon Test.

dizziness than those who practice some type of physical activity. ${ }^{42}$ In the present study, over half of the elderly people did not perform any physical activity and, among those who did, walking was the most common.

It is important to evaluate the influence of visual, somatosensory, and vestibular systems in the maintenance of static balance to comprehend sensorial contribution to postural control. This evaluation is possible through stimuli to the individual, which involve alterations in visual input and changes in the supporting surface. Individuals with BPPV can present low sway velocity when on a firm surface, with eyes open or closed, when compared with healthy individuals, due to greater reliance on visual and proprioceptive systems to maintain stability. In other words, they compensate vestibular dysfunction by using visual and proprioceptive inputs to maintain a standing position over time. ${ }^{46}$ In this study, we obtained lower sway velocity within the same conditions found in the previously mentioned study. However, BPPV patients strongly depend on their vestibular system to maintain balance when they receive visual input and/ or there are changes in proprioceptive input. The lack of accuracy of the vestibular information from one side can cause inefficiency in sensory organization and an abnormal vestibule-spine response. There is an increase in postural stability challenges when the support base is reduced, in which case BPPV patients present an increase in the sway velocity. ${ }^{46}$ According to the sensorial interaction test, we observed similar results in this study, as the conditions that combined alterations in the proprioceptive inputs and deprivation of the visual inputs resulted in the highest sway velocities. Therefore, in the

Table 5 Static and dynamic postural balance performance in elderly BPPV patients at initial evaluation and after modified Epley maneuver (1-week assessment)

\begin{tabular}{|c|c|c|c|}
\hline & Initial Evaluation & 1 week & $p$ \\
\hline \multicolumn{4}{|l|}{ Static balance } \\
\hline \multicolumn{4}{|l|}{$\mathrm{mCTSIB}\left({ }^{\circ} / \mathrm{s}\right)$} \\
\hline Firm EO & $0.4(0.1-0.9)$ & $0.4(0.1-1.3)$ & 0.530 \\
\hline Firm EC & $0.5(0.2-1.3)$ & $0.4(0.1-1.7)$ & 0.503 \\
\hline Foam EO & $1.1(0.6-2.4)$ & $0.7(0.4-1.9)$ & $0.004^{*}$ \\
\hline Foam EC & $2.3(1-6)$ & $1.7(0.6-6)$ & $0.028^{*}$ \\
\hline Composition & $1.1(0.6-4.5)$ & $0.8(0.5-2)$ & $0.011^{*}$ \\
\hline \multicolumn{4}{|l|}{ US $\left({ }^{\circ} / \mathrm{s}\right)$} \\
\hline Eyes open & $12(1-12)$ & $5.1(1.1-12)$ & 0.441 \\
\hline Eyes closed & $12(8.5-12)$ & $12(5.5-12)$ & 0.276 \\
\hline \multicolumn{4}{|l|}{ Dynamic balance } \\
\hline \multicolumn{4}{|l|}{ LOS } \\
\hline $\operatorname{MVL}\left({ }^{\circ} / \mathrm{s}\right)$ & $1.9(0-5)$ & $2.6(0.8-4.7)$ & $0.013^{*}$ \\
\hline EPE (\% LOS) & $44.5(0-80)$ & $45.5(30-82)$ & 0.107 \\
\hline MXE (\% LOS) & $64(0-97)$ & 71 (36-95) & $0.047^{*}$ \\
\hline $\mathrm{DCL}(\% \mathrm{LOS})$ & $51(0-81)$ & $59(0-78)$ & 0.092 \\
\hline \multicolumn{4}{|l|}{ Tandem walk } \\
\hline Speed $(\mathrm{cm} / \mathrm{s})$ & $16.3(9-26.8)$ & $18.6(10.7-30.4)$ & 0.683 \\
\hline End Sway $\left({ }^{\circ} / \mathrm{s}\right)$ & $7.75(4.8-13.1)$ & $6.2(4.8-14.7)$ & 0.177 \\
\hline DGI & $16(8-22)$ & $19(11-23)$ & $0.004^{*}$ \\
\hline
\end{tabular}

Abbreviations: DCL, Directional Control; DGI, Dynamic Gait Index; EC, Eyes Closed; EO, Eyes Open; EPE, Endpoint Excursion; LOS, Limits of Stability Test; mCTSIB, modified Clinical Test of Sensory Integration on Balance; MVL, Movement Velocity; MXE, Maximum Excursion; US, Unilateral Stance Test.

The values represent the Median (amplitude); ${ }^{*} p<0.05$, by the non-parametric Wilcoxon Test. 
unilateral stance test, the participants in this study obtained higher sway velocities than those values demonstrated in the study by Chang et al., ${ }^{46}$ possibly due to the difference in age groups of the samples studied, considering the intrinsic influence of the aging process in the sample from the present study.

In the Tandem Walk test, the speed was lower due to a reduction in the support base and center of gravity deceleration was required to maintain postural balance at the end of the Tandem Walk. However, according to Chang et al., ${ }^{46}$ who evaluated dynamic balance through the Tandem Walk test, individuals with BPPV presented a lower gait speed and a greater final speed compared with healthy individuals. The increased end sway velocity observed in BPPV patients was attributed to vestibular dysfunction in detecting linear deceleration. $^{46}$ The present study corroborated Chang et al., ${ }^{46}$ although this study recorded lower values of walking speed and greater values of final speed, possibly due to the older age group composing the sample of the present study.

Elderly individuals with vestibular dysfunction may present reduced LOS and use ankle and hip strategies to maintain postural control, which can cause functional incapacity and increase the risk of falling. Studies have linked ORM to a considerable increase in LOS, which consequently reduce such risks. ${ }^{47,48}$ In this study, there was a significant improvement in two aspects of LOS, movement velocity and in the maximum excursion after one treatment session. It was impossible to infer whether the LOS values were lower or higher than normal, because there were no studies with LOS data obtained from the Balance Master in elderly BPPV patients compared with healthy individuals from the same age group.

Regarding functional evaluation of gait measured by DGI, we perceived that the study participants significantly improved their DGI scores one week post-ORM, even as the median score after one week of treatment demonstrated that the participants in our study continued to present an increased risk of falls. This is in accordance with Shumway-Cook et al., ${ }^{49}$ who showed that DGI scores of 19 or more indicate increased risk of falls in elderly residents of the community.

The main limitations to the study were the absence of a control group of healthy elderly people to compare with the results found herein and the small sample size, which rendered it impossible to establish statistical associations between quantity of medications, number of diseases, vertiginous symptoms, and balance data. It is, therefore, necessary to undertake further studies that seek to relate the factors that influence BPPV and their repercussions in the activities performed by the elderly in their daily activities. Dizziness is multifactorial in its cause and identification requires treatment in all spheres: physical, psychological, and affective.

\section{Conclusion}

The results suggest that, despite the short-term beneficial clinical effects observed in dizziness symptoms and quality of life after the Otolithic Repositioning Maneuver, the majority of patients was not cured post-ORM and not all aspects of postural balance improved, which pose greater challenges to the motor and sensorial systems. Therefore, a longer followup period and a multidisciplinary team are required to establish a comprehensive care program for elderly patients with dizziness complaints.

\section{References}

1 Prata MG, Scheicher ME. Correlation between balance and the level of functional independence among elderly people. Sao Paulo Med J 2012;130(2):97-101

2 Júnior PF, Barela JA. Changes in Elderly Postural Control System Functioning. Use of Visual Information Rev Port Cien Desp 2006; 6(1):94-105

3 Gazzola JM, Perracini MR, Ganança MM, Ganança FF. Functional balance associated factors in the elderly with chronic vestibular disorder. Braz J Otorhinolaryngol 2006;72(5):683-690

4 Inouye SK, Studenski S, Tinetti ME, Kuchel GA. Geriatric syndromes: clinical, research, and policy implications of a core geriatric concept. J Am Geriatr Soc 2007;55(5):780-791

5 Woollacott M, Shumway-Cook A. Attention and the control of posture and gait: a review of an emerging area of research. Gait Posture 2002;16(1):1-14

6 Lacour M, Bernard-Demanze L, Dumitrescu M. Posture control, aging, and attention resources: models and posture-analysis methods. Neurophysiol Clin 2008;38(6):411-421

7 von Brevern M, Radtke A, Lezius F, et al. Epidemiology of benign paroxysmal positional vertigo: a population based study. J Neurol Neurosurg Psychiatry 2007;78(7):710-715

8 Marom T, Oron Y, Watad W, Levy D, Roth Y. Revisiting benign paroxysmal positional vertigo pathophysiology. Am J Otolaryngol 2009;30(4):250-255

9 Kerrigan MA, Costigan MF, Blatt KJ, Mathiason MA, Domroese ME. Prevalence of benign paroxysmal positional vertigo in the young adult population. PM R 2013;5(9):778-785

10 Dorigueto RS, Ganança MM, Ganança FF. The number of procedures required to eliminate positioning nystagmus in benign paroxysmal positional vertigo. Braz J Otorhinolaryngol 2005; 71(6):769-775

11 Vaz DP, Gazzola JM, Lança SM, Dorigueto RS, Kasse CA. Clinical and functional aspects of body balance in elderly subjects with benign paroxysmal positional vertigo. Braz J Otorhinolaryngol 2013; 79(2):150-157

12 Chang W-C, Yang Y-R, Hsu L-C, Chern CM, Wang RY. Balance improvement in patients with benign paroxysmal positional vertigo. Clin Rehabil 2008;22(4):338-347

13 Parnes LS, Agrawal SK, Atlas J. Diagnosis and management of benign paroxysmal positional vertigo (BPPV). CMAJ 2003;169(7):681-693

14 Dix MR, Hallpike CS. The pathology symptomatology and diagnosis of certain common disorders of the vestibular system. Proc $R$ Soc Med 1952;45(6):341-354

15 Kasse CA, Santana GG, Scharlach RC, Gazzola JM, Branco FCB, Doná F. Results from the balance rehabilitation unit in benign paroxysmal positional vertigo. Braz J Otorhinolaryngol 2010;76(5):623-629

16 Stambolieva K, Angov G. Postural stability in patients with different durations of benign paroxysmal positional vertigo. Eur Arch Otorhinolaryngol 2006;263(2):118-122

17 Kao CL, Hsieh WL, Chern CM, Chen LK, Lin MH, Chan RC. Clinical features of benign paroxysmal positional vertigo (BPPV) in Taiwan: differences between young and senior age groups. Arch Gerontol Geriatr 2009;49(2, Suppl 2):S50-S54

18 Monteiro SRG, Ganança MM, Ganança FF, Ganança CF, Caovilla HH. Balance Rehabilitation Unit (BRU ${ }^{\mathrm{TM}}$ ) posturography in benign paroxysmal positional vertigo. Braz J Otorhinolaryngol 2012; 78(3):98-104 
19 De Castro SM, Perracini MR, Ganança FF. Dynamic Gait Index Brazilian version. Braz J Otorhinolaryngol 2006;72(6):817-825

20 Pollak L, Davies RA, Luxon LL. Effectiveness of the particle repositioning maneuver in benign paroxysmal positional vertigo with and without additional vestibular pathology. Otol Neurotol 2002; 23(1):79-83

21 Lee SH, Kim JS. Benign paroxysmal positional vertigo. J Clin Neurol 2010;6(2):51-63

22 Soto-Varela A, Santos-Perez S, Rossi-Izquierdo M, Sanchez-Sellero I. Are the three canals equally susceptible to benign paroxysmal positional vertigo? Audiol Neurootol 2013;18(5):327-334

23 Gold DR, Morris L, Kheradmand A, Schubert MC. Repositioning maneuvers for benign paroxysmal positional vertigo. Curr Treat Options Neurol 2014;16(8):307

24 Lança SM, Gazzola JM, Kasse CA, Branco-Barreiro FC, Vaz DP, Scharlach RC. Body balance in elderly patients, 12 months after treatment for BPPV. Braz J Otorhinolaryngol 2013;79(1):39-46

25 Fife TD, Iverson DJ, Lempert T, et al; Quality Standards Subcommittee, American Academy of Neurology. Practice parameter: therapies for benign paroxysmal positional vertigo (an evidence-based review): report of the Quality Standards Subcommittee of the American Academy of Neurology. Neurology 2008; 70(22):2067-2074

26 Angeli SI, Hawley R, Gomez O. Systematic approach to benign paroxysmal positional vertigo in the elderly. Otolaryngol Head Neck Surg 2003;128(5):719-725

27 Mandalà M, Santoro GP, Asprella Libonati G, et al. Double-blind randomized trial on short-term efficacy of the Semont maneuver for the treatment of posterior canal benign paroxysmal positional vertigo. J Neurol 2012;259(5):882-885

28 Resende CR, Taguchi CK, Almeida JGD, Fujita RR. Vestibular rehabilitation in elderly patients with benign paroxysmal positional vertigo. Braz J Otorhinolaryngol 2003;69(4):535-540

29 Salvinelli F, Trivelli M, Casale M, et al. Treatment of benign positional vertigo in the elderly: a randomized trial. Laryngoscope 2004;114(5):827-831

30 Toupet M, Ferrary E, Bozorg Grayeli A. Effect of repositioning maneuver type and postmaneuver restrictions on vertigo and dizziness in benign positional paroxysmal vertigo. ScientificWorldJournal 2012;2012:162123

31 Simoceli L, Bittar RSM, Greters ME. Posture restrictions do not interfere in the results of canalith repositioning maneuver. Braz J Otorhinolaryngol (Engl Ed) 2005;71(1):55-59

32 von Brevern M, Seelig T, Radtke A, Tiel-Wilck K, Neuhauser H, Lempert T. Short-term efficacy of Epley's manoeuvre: a double-blind randomised trial. J Neurol Neurosurg Psychiatry 2006;77(8):980-982

33 Gazzola JM, Ganança FF, Aratani MC, Perracini MR, Ganança MM. Clinical evaluation of elderly people with chronic vestibular disorder. Braz J Otorhinolaryngol 2006;72(4):515-522

34 Parham K, Leonard G, Feinn RS, Lafreniere D, Kenny AM. Prospective clinical investigation of the relationship between idiopathic benign paroxysmal positional vertigo and bone turnover: a pilot study. Laryngoscope 2013;123(11):2834-2839

35 Yu S, Liu F, Cheng Z, Wang Q. Association between osteoporosis and benign paroxysmal positional vertigo: a systematic review. BMC Neurol 2014;14(1):110

36 Bhattacharyya N, Baugh RF, Orvidas L, et al; American Academy of Otolaryngology-Head and Neck Surgery Foundation. Clinical practice guideline: benign paroxysmal positional vertigo. Otolaryngol Head Neck Surg 2008;139(5, Suppl 4):S47-S81

37 Gassmann KG, Rupprecht R; IZG Study Group. Dizziness in an older community dwelling population: a multifactorial syndrome. J Nutr Health Aging 2009;13(3):278-282

38 Gomez F, Curcio CL, Duque G. Dizziness as a geriatric condition among rural community-dwelling older adults. J Nutr Health Aging 2011;15(6):490-497

39 Moreira Bittar RS, Simoceli L, Bovino Pedalini ME, Bottino MA. The treatment of diseases related to balance disorders in the elderly and the effectiveness of vestibular rehabilitation. Braz J Otorhinolaryngol 2007;73(3):295-298

40 Gazzola JM, Ganança FF, Aratani MC, Perracini MR, Ganança MM. Circumstances and consequences of falls in elderly people with vestibular disorder. Braz J Otorhinolaryngol 2006;72(3):388-392

41 De Stefano A, Dispenza F, Suarez H, et al. A multicenter observational study on the role of comorbidities in the recurrent episodes of benign paroxysmal positional vertigo. Auris Nasus Larynx 2014; 41(1):31-36

42 Silva TO, Freitas RS, Monteiro MR, Borges SM. Evaluation of physics capacity and falls in elderly active and sedentary of community. Journal of the Brazilian Society of Internal Medicine 2010;8(5): 392-398

43 Bazoni JA, Mendes WS, Meneses-Barriviera CL, et al. Physical activity in the prevention of benign paroxysmal positional vertigo: probable association. Int Arch Otorhinolaryngol 2014;18(4): 387-390

44 Handa PR, Kuhn AMB, Cunha F, Schafflel R, Ganança FF. Qualidade de vida em pacientes com vertigem posicional paroxística benigna e/ou doença de Ménière. Braz J Otorhinolaryngol 2005;71(6):776-783

45 Pereira AB, Santos JN, Volpe FM. Effect of Epley's maneuver on the quality of life of paroxismal positional benign vertigo patients. Braz J Otorhinolaryngol 2010;76(6):704-708

46 Chang WC, Hsu LC, Yang YR, Wang RY. Balance ability in patients with benign paroxysmal positional vertigo. Otolaryngol Head Neck Surg 2006;135(4):534-540

47 Horak FB. Clinical assessment of balance disorders. Gait Posture 1997;6(1):76-84

48 Kasse CA, Santana GG, Branco-Barreiro FCA, et al. Postural control in older patients with benign paroxysmal positional vertigo. Otolaryngol Head Neck Surg 2012;146(5):809-815

49 Shumway-Cook A, Baldwin M, Polissar NL, Gruber W. Predicting the probability for falls in community-dwelling older adults. Phys Ther 1997;77(8):812-819 